\title{
Movimentos pendulares das cidades interioranas de porte médio de Cascavel e Toledo, no Paraná
}

\author{
Cristiano Stamm* \\ Jefferson Andronio Ramundo Staduto**
}

\begin{abstract}
O objetivo desse artigo é examinar o fenômeno do movimento pendular de trabalhadores intermunicipais entre as cidades interioranas de porte médio de Cascavel e Toledo, localizadas na Mesorregião Oeste do Estado do Paraná. A dinâmica econômico-populacional das distintas regiões do interior do Brasil vem imprimindo novas modalidades de deslocamentos populacionais, as quais eram quase exclusivas dos grandes centros urbanos. Os estudos dessa natureza tornam-se importantes, pois levantam informações relevantes para o planejamento urbano-regional e no ordenamento da dinâmica territorial. O movimento pendular observado nesse estudo é do tipo cruzado, o que significa que há movimento casa-trabalho originado nas duas cidades, em razão de ambas serem pólos regionais. O resultado da pesquisa evidenciou que a rede primária de proteção social (a família) é um fator importante e, em particular, das cidades de porte médio, como é caso de Cascavel e Toledo. O fluxo de trabalhadores pendulares entre Cascavel e Toledo apresenta um papel fundamental no desenho da rede urbana da região. Desta forma, verificou-se que algumas questões urbanas apresentadas nos grandes centros urbanos e nas regiões metropolitanas do país, tais como os movimentos pendulares, são também temas importantes para as cidades de menor porte populacional.
\end{abstract}

Palavras-chave: Movimento pendular. Cidades de porte médio. Rede urbana.

\section{Introdução}

O aumento dos fluxos de trabalhadores entre cidades aguça o interesse sobre esse tema. A mobilidade populacional dessa natureza apresenta valor estratégico nas transformações socioeconômicas e físicas do território e, conseqüentemente, reflete no bem-estar da população. Este movimento também é fundamental para os citadinos, e, segundo Handson e Pratt (apud WEBER; KWAN, 2003), a ligação casa-trabalho é uma atividade básica para a população, pois, por intermédio desse movimento, as pessoas podem participar do mercado trabalho. Sendo assim, trata-se de um processo essencial para as cidades e regiões.

Os temas movimento e acessibilidade urbana assumem importância como instrumento para dimensionar uma unidade

\footnotetext{
* Economista e Mestre em Desenvolvimento Regional e Agronegócio pela Universidade Estadual do Oeste do Paraná - Unioeste.

** Doutor em Economia Aplicada pela Esalq/USP. Pesquisador do CNPq, professor adjunto do curso de Ciências Econômicas e do Programa de Pós-Graduação em Desenvolvimento Regional e Agronegócio da Unioeste. Pesquisador do Grupo de Pesquisa em Agronegócio e Desenvolvimento Regional (Gepec).
} 
regional. A OECED (2002) define uma região funcional ${ }^{1}$ em termos da extensão do mercado de trabalho, ultrapassando os limites administrativos dos municípios. 0 movimento pendular é utilizado como instrumento para dimensioná-la. De acordo com a OECED (2002, p. 11), "o delineamento de região funcional em muitos países membros [OECED] está baseado no movimento pendular". Critérios distintos podem ser considerados para descrever os movimentos pendulares, tais como freqüência da viagem, distância a ser percorrida, entre outros. No entanto, independente dessas variações, 22 países membros da OECED, a partir do movimento pendular, utilizam a extensão do mercado de trabalho para delimitar uma região funcional.

Os estudos sobre movimento pendular também levantam informações relevantes para o planejamento urbano-regional e no ordenamento da dinâmica territorial. Reolon (2007), baseado no estudo de Galvão et. al. (1969), que utilizaram o movimento pendular para dimensionar metrópoles institucionais, aplicou essa mesma metodologia para mensurar uma unidade regional no interior do país, a partir do contexto de metropolização.

Conforme George (1983), o movimento pendular não consiste mais em um fenômeno próprio da vida nos grandes centros urbanos, mas sim em um fenômeno de irradiação exterior às cidades e suas hinterland ${ }^{2}$ (áreas de influências), podendo ser estudado em conjunto com outras formas de extensão urbana, dentro do quadro da definição e da delimitação das redes urbanas. ${ }^{3}$ Baeninger (1996) faz uma constatação de mesma natureza so- bre a dinâmica econômico-populacional das distintas regiões do interior do Brasil. A autora observa que os movimentos pendulares fazem parte de novas modalidades de deslocamentos populacionais, as quais eram quase exclusivas aos grandes centros urbanos. Porém, são pouco presentes na literatura estudos que relacionam esses movimentos com as cidades interioranas de porte médio. ${ }^{4}$

Ainda não se sabe muito sobre a influência da rede urbana nos movimentos pendulares em municípios de menor porte. A maioria dos estudos e pesquisas ocorre nas áreas metropolitanas, onde as circunstâncias do transporte e do tamanho populacional das cidades são completamente diferentes daquelas existentes em áreas não-metropolitanas (VANDERSMISSEN; VILLENEUVE; THÉRIAULT, 2003).

Tendo em vista que os grandes centros urbanos têm sido objetos de vários estudos realizados no Brasil e no exterior, ${ }^{5}$ esse trabalho está trazendo à luz os municípios de porte médio, que estão evidenciando novas tendências urbanas, causadas pelo fluxo de trabalhadores entre cidades. Vale ressaltar que a análise realizada neste artigo focouse nas cidades de porte médio, e não nas pequenas, devido à necessidade de uma inevitável escala mínima urbana, principalmente na oferta de bens e serviços.

Considerando estes apontamentos iniciais, o objetivo central deste artigo é examinar o fenômeno do movimento pendular de trabalhadores intermunicipais entre as cidades interioranas de porte médio de Cascavel e Toledo, no interior do Estado do Paraná, mais precisamente na Mesorregião do Oeste paranaense.

\footnotetext{
1 Uma região funcional é uma unidade territorial resultado da organização das relações sociais econômicas, sendo que suas fronteiras não refletem parte geográfica ou histórica. É uma subdivisão dos territórios. O mais típico conceito usado na definição de uma região funcional é o mercado de trabalho (OECED, 2002).

2 Segundo INE (2004), a hinterland (ou área de influência) de uma função central (num determinado centro urbano) corresponde ao lugar geométrico onde se encontram os usuários da função central.

3 Segundo Ipea et al. (1999), entende-se, no Brasil, como rede urbana um conjunto de cidades de diferentes categorias que se inter-relacionam entre elas e as respectivas áreas rurais, dentro de um sistema hierárquico, mantendo uma dependência econômica, cultural, política e social, por meio da oferta de bens e prestação de serviços.

${ }^{4}$ São aquelas cidades com população entre 100 mil e 500 mil habitantes. As cidades de porte médio, a partir da década de 60, vêm aumentando consideravelmente sua participação no total dos municípios do país, na distribuição regional da população e, de modo geral, na influência da rede urbana nacional (BRITO; HORTA; AMARAL, 2001).

5 Para saber mais sobre a ocorrência desse tipo de fenômeno nos grandes centros urbanos, ver: Pisco (1997); Carvalho e Barreta (1998); Antico (2000; 2003); Baeninger (1996); Magalhães e d'Avila (1996), INE (2003a e 2003b), entre outros.
} 
Assim, na primeira parte deste artigo, encontra-se uma breve abordagem sobre os movimentos pendulares, trazendo alguns aspectos introdutórios sobre a literatura. A seguir, são descritas e discutidas algumas características do eixo Cascavel-Toledo, bem como o procedimento metodológico da pesquisa empírica. Posteriormente, apresenta-se a análise empírica desse artigo, a partir dos dados da pesquisa, além das conclusões realizadas.

\section{Os movimentos pendulares}

No Brasil, as transformações urbanas ocorridas nas últimas décadas, tais como inserção da mulher no mercado de trabalho, novas formas de moradias e alterações na composição familiar, constituem elementos importantes para interpretação das mudanças demográficas e socioeconômicas. O panorama da mobilidade espacial da população brasileira foi modificado basicamente na década de 80 , apresentando-se diversificado e com implicações mais determinadas na configuração e estruturação das cidades. Atualmente, os movimentos migratórios passam a apresentar novas características, reflexo do novo panorama socioeconômico imerso num contexto amplamente urbanizado e de áreas rurais inseridas numa dinâmica de modernização tecnológica. Aliado a esses fatores, destacase o papel preponderante da inovação tecnológica nos setores de transporte e dos meios de comunicação. Segundo Baeninger (1996, p. 681):

os clássicos fatores de expulsão e de atração de população dentro de um mesmo contexto urbano-metropolitano, bem como a definição de origem e destino de determinados fluxos não tem o mesmo significado que esses termos representavam quando se tratava de analisar os grandes movimentos ruraisurbanos, que marcaram o crescimento e a concentração da população em áreas metropolitanas.

As formas de redistribuição espacial da população estão associadas:

tanto ao crescimento inter-regional como dimensão territorial do processo de urbanização, quanto intra-urbano regional - como a expressão local dos processos sociais, onde fenômenos semelhantes aos metropolitanos vêm ocorrendo, porém, noutro espaço, noutro tempo e noutra escala (BAENINGER, 1999, p. 74).

Ainda de acordo com a autora, esses fenômenos de movimentos populacionais já são visíveis, principalmente nos pólos regionais e suas hinterland. Os movimentos populacionais estão se espraiando pelo território nacional e relacionam-se a várias determinações da vida social, entre as quais o aspecto econômico passou a ser peça fundamental, porém não a única, dos movimentos populacionais.

Segundo George (1983), a mobilidade da população urbana manifesta-se em dois níveis de grande importância: sob a configuração de uma maior ou menor volubilidade de moradia; e sob a forma de movimentos diários da população. No entanto, deve-se ressaltar que essas duas situações, por muitas vezes, estão fortemente relacionadas.

A mobilidade populacional urbana, com ênfase na moradia, revela uma característica de pessoas ou trabalhadores que, por motivos econômicos, ocupam uma habitação de menor custo, de tal magnitude que geram a mobilidade da população internamente à cidade, considerando o grande peso do fator econômico em seu deslocamento. Conforme aumentam as necessidades do indivíduo - como, por exemplo, o nascimento de um filho -, reduz-se o orçamento e, conseqüentemente, essa alteração pode ser acompanhada por uma mudança de local de moradia. Esses movimentos também fazem parte do complemento da mobilidade populacional de uma cidade para outra, sendo uma das características mais gerais da vida urbana.

Atualmente predominam dois tipos de moradias: aquela destinada às classes de renda média e alta, que "fogem" das metrópoles em busca de qualidade de vida; e aquela voltada para a população de baixa renda, que se refugia nas periferias, devido ao elevado custo de habitação na área central da cidade (CARLOS, 2001; PISCO, 1997).

De qualquer forma, na maior parte dos grandes centros urbanos, tornou-se difícil encontrar uma residência adequada 
ao orçamento familiar; as habitações disponíveis localizam-se, cada vez mais, nas periferias desses centros. Comumente, essa distância leva as pessoas a ultrapassarem os limites administrativos dos municípios onde desempenham diariamente suas atividades profissionais.

O outro aspecto da mobilidade urbana, segundo George (1983, p. 190), é o movimento diário da população, que "tem como causa a crescente separação geográfica entre os diversos lugares de atividade e os lugares de residência nas grandes cidades contemporâneas. Resulta de uma simultaneidade de movimentos de mesma natureza e da distribuição horária contígua, mas de componentes geográficos diferentes". Ainda segundo o autor, na maioria das vezes esses movimentos são centrípetos de manhã e centrífugos no final da tarde e início da noite.

Conforme Horner (2003), a ligação casa-trabalho é, basicamente, entendia como uma atividade pela qual as pessoas podem participar de um mercado de trabalho e, desta forma, suprir suas necessidades vitais. As pessoas têm possibilidades e condições para viver onde desejam, enquanto ainda existe capacidade de se envolver em uma vida ativa, incluindo o movimento pendular ${ }^{6}$ de longa distância.

Esse tipo de movimento, na década de 50, conforme George (1983), era muito comum em cidades de grande porte. Ainda segundo esse autor, em Paris, por exemplo, estimava-se que 2,2 milhões de pessoas ativas trabalhavam fora de seu distrito ou município de residência.

Segundo Beaujeu-Garnier (1974 p. 297), entre as décadas de 50 e 60, embora:

as migrações de mão-de-obra periódicas estivessem declinando quase em toda parte, os movimentos diários estavam constantemente aumentando quer em número quer em distância; esses dois fatos são apenas duas manifestações da influência do progresso técnico sobre a vida e a atividade humana. Os modernos meios de transporte [estavam] favorecendo o que se tornou necessidade econômica, isto é, a concentração dos meios de produção e o crescimento das cidades.

Atualmente, segundo o INE (2003b, p. 8), a intensificação e a complexidade da mobilidade populacional não são apenas resultado da "evolução dos transportes, mas, também, são conseqüências de transformações sociais e econômicas, designadamente com a chegada das muIheres ao mercado de trabalho, as novas organizações de trabalho (tempo parcial, turnos), a periurbanização ${ }^{7}$ e a evolução das mentalidades".

Atualmente, no Brasil, os deslocamentos de curta distância passaram a ter certa predominância no contexto da economia brasileira (BAENINGER, 1996; ANTICO, 2003). Segundo Antico (2003), os dados do Censo Demográfico de $2000^{8}$ revelaram que, no país, 7,4 milhões de pessoas trabalhavam ou estudavam fora de seu município de residência, realizando, assim, o movimento pendular.

A ocorrência da pendulariedade é mais visível nos grandes centros urbanos brasileiros, como São Paulo, Rio de Janeiro, Curitiba, Belo Horizonte, Porto Alegre, entre outros. Um exemplo é a dimensão da mobilidade populacional intermunicipal da Região Metropolitana de São Paulo (RMSP), onde, conforme a Companhia do Metropolitano de São Paulo - CMSP (1987 e 1997) citado por Antico (2000), cerca de 925,2 mil pessoas faziam, em 1987, os movimentos pendulares intermunicipais, o que representava $18 \%$ da

\footnotetext{
6 Já alguns autores, como Matos (1993), chamam esse tipo de fenômeno de migrações pendulares. Porém, algumas críticas surgem à denominação de migrações pendulares, pois, para alguns autores, a palavra migrações possui um significado mais abrangente. Segundo The Determinants... (1973), citado por Carvalho e Rigotti (1998), excluem-se das migrações apenas os indivíduos que não se estabelecem permanentemente no local de destino. Dessa forma, esses autores atribuem para o restante apenas a palavra "movimentação" populacional e, nesse caso em específico, de movimento pendular. Desse modo, enquanto não ocorrer de fato a migração, segundo o IBGE (2000), esses deslocamentos não passam de "movimentos" pendulares. Segundo Antico (2003, p. 19), "há um certo consenso, atualmente, entre os estudiosos de população, sobre o fato de que os deslocamentos pendulares não devem ser considerados migração, pois os dois fenômenos possuem conceitos distintos".

7 Mais detalhes sobre periurbanização, ver Moreira (2005); Ipea et al. (2002); Dematteis (2002) e Vales (2004).

8 Resultados da Amostra - Migração e Deslocamento - divulgados pelo IBGE (2003).
} 
população ocupada daquela região. Em 1997, esse número aumentou para 1,3 miIhão, ou $18,7 \%$ dos ocupados na RMSP.

Para George (1983), o distanciamento das atividades econômicas faz com que o recrutamento da mão-de-obra dos diversos setores de atividades não se limite mais à cidade ou ao aglomerado urbano. Esse distanciamento, ainda, leva o trabalhador a realizar deslocamentos diários, constituindo um fenômeno nem sempre de fácil solução do ponto de vista tanto individual como coletivo. Esses deslocamentos diários podem ocorrer de forma individual, como executivos e altos funcionários com veículos motorizados, por meio de transportes coletivos, privados ou públicos, utilizados por funcionários, podendo também ser incorporados nesses deslocamentos diários os estudantes de ensinos médio e superior. Segundo o INE (2003b), o deslocamento cotidiano de trabalhador figura entre um dos mais conhecidos desses movimentos, por ser o mais freqüente e ritmado.

Esses movimentos "que caracterizam mobilidades de curta duração [...] dizem-se pendulares porque, realizados a horas mais ou menos fixas, refletem a estruturação do espaço e a existência ou não de hierarquias" (INE, 2003b, p. 7). Segundo Beaujeu-Garnier (1974, p. 284), é "devido à sua feição característica - um movimento de vaivém semeIhante à oscilação de um pêndulo -" que esse fenômeno recebe a denominação de movimento pendular.

A partir dessa comparação, segundo o INE (2003a, p. 11), a expressão:

\begin{abstract}
"movimentos pendulares" é habitualmente utilizada para designar os movimentos quotidianos das populações entre o local de residência e o local de trabalho ou estudo. $O$ conceito de movimento pendular encerra, na sua forma mais simples, duas deslocações de uma pessoa entre dois pontos do espaço geográfico: uma de ida para o local de trabalho ou estudo e outra de retorno ao local de residência. Deste modo, antes de mais, o movimento pendular é uma questão funcional que resulta da organização do território e da não coincidência entre o local de residência e os locais de trabalho ou estudo.
\end{abstract}

Segundo Patarra et al. (2000), os movimentos populacionais intra-regionais e a mobilidade pendular são, normalmente, fenômenos de intensidade expressiva e com importantes implicações nas dinâmicas demográficas destas áreas. Nesse sentido, o movimento pendular,

\begin{abstract}
além de registrar a movimentação cotidiana no espaço metropolitano, é a evidência mais clara de como se constitui o mercado de trabalho na região metropolitana e a segmentação dos locais de moradia e de trabalho, que se estabelecem por lógicas distintas neste aglomerado urbano (MONTALI, 1991, p. 8 apud ANTICO, 2003, p. 18).
\end{abstract}

Segundo Vandersmissen, Villeneuve e Thériault (2003), há um vigoroso debate sobre o papel das variáveis que determinam os movimentos pendulares. Para vários autores, existe relação entre a forma urbana e a duração do tempo de viagem dos trabalhadores e estudantes que fazem o movimento pendular, mas essa relação ainda é mal compreendida, principalmente porque poucos estudos puderam documentar mudanças estruturais no longo prazo, com dados locacionais (ou de localização) suficientemente detalhados.

Gordon, Kumar e Richardson (1989) afirmaram que os movimentos pendulares tendem a ser mais longos e demorados em cidades grandes do que nas menores, mas esta relação simples é muito influenciada pela estrutura espacial metropolitana. Segundo Grando (2005), os movimentos pendulares têm sua intensidade condicionada ao tamanho das cidades - quanto maiores são os centros urbanos, maiores tendem a ser os fluxos pendulares, pois, como já mencionado, o mercado imobiliário encarece o solo das áreas centrais.

Ommeren, Rietveld e Nijkamp (1998) ressaltam que geógrafos e economistas igualmente argumentam que a relação entre a mobilidade de emprego e a residencial depende da extensão da distância do movimento considerado pelo cidadão ou pelo núcleo familiar. Desse modo, a pendulariedade pode levar à permanência definitiva do indivíduo numa determinada região, ou seja, à migração interna.

Segundo George (1983) e BeaujeuGarnier (1974), a decisão para o trabalhador 
migrar também está condicionada por outros motivos: sistema de transporte e de circulação em grande escala, cuja utilização só é efetiva durante poucas horas por dia, "na hora do rush"; custo do transporte coletivo; riscos de acidentes, devido à grande circulação de pessoas e veículos, que podem resultar na interrupção do trabalho e atrasos; tempo despendido na locomoção; e acessibilidade propiciada pelo sistema público de transporte.

Apesar desses motivos expostos, relacionados à decisão definitiva de migrar, segundo Renkow e Hoover (2000, p. 267, tradução nossa), "o movimento pendular e o comportamento migratório estão associados, e isto é freqüentemente ignorado nos estudos que os analisam independentemente um do outro". Por exemplo, na pesquisa empírica de Renkow, Hoover e Yoder (1996), realizada no estado americano da Carolina do Norte, revelou a existência de relação entre movimento pendular e migração, e no modelo analítico proposto, além da distância entre um distrito e outro e o custo da moradia, considerou o salário do trabalhador.

De acordo com os autores, os trabaIhadores mais especializados tendem a receber melhores salários e realizarem com mais freqüência os movimentos pendulares. Porém, segundo Andrade e Serra (1997), isto deixa de ser algo simples e passa a ser mais complexo a partir do momento em que vão se acumulando as externalidades negativas ligadas ao meio social, tais como qualidade de vida, segurança, assistência hospitalar, transporte, entre outros. Dessa forma, os movimentos pendulares podem ser estudados sob várias perspectivas: econômica, social, geográfica, histórica ou pela suas junções, entre outras.

Essa multidisciplinariedade, considerando-se as novas formas de urbanização, deve ser entendida como um processo em que a grande cidade ou a cidade-sede interage com a sua área de influência as aglomerações regionais -, mantendo vínculos de relações por meio do setor de serviços, emprego, insumos para as atividades econômicas, local para moradia, entre outros (BAENINGER, 1999). Dessa forma, segundo a autora, a mobilidade intra-urbana constitui um dos principais elementos da formação e consolidação de tais espaços urbanos.

Com certa predominância dos movimentos intra-urbanos, num contexto de dispersão e, ao mesmo tempo, de polarização regional,

os movimentos pendulares da população, constituindo especialmente um tipo de mobilidade intra-urbana, tornam-se uma dimensão importante na decisão de mudar ou não da localidade de residência, uma vez que com este movimento - fruto do processo de urbanização (especialmente com a melhoria das vias de transporte) e das novas formas de redistribuição espacial da população - a mudança de emprego não corresponde necessariamente a uma mudança de residência [...] (BAENINGER, 1999, p.75).

A maior parte das pesquisas empíricas sobre movimento pendular adota como áreas de estudo os grandes centros urbanos, devido ao acúmulo de trabalhadores que vivem nesses locais e que fazem diariamente esse movimento. No entanto, os centros intermediários (cidades de porte médio) do país, segundo Brito, Horta e Amaral (2001), apresentam taxas de crescimento mais elevadas, quando comparados às metrópoles, e estão assumindo papel importante no planejamento urbano e regional. A mobilidade populacional diária não é uma tendência exclusiva dos grandes centros, e é nesse sentido que este artigo apresenta a ocorrência e sua freqüência nos centros de porte médio de Cascavel e Toledo, bem como a inserção na rede urbana da Mesorregião Oeste do Paraná.

\section{Caracterização do eixo Cascavel-Toledo}

As cidades de Cascavel e Toledo localizam-se na Mesorregião Oeste do Paraná e estão distantes entre si cerca de $35 \mathrm{~km}$. Essa mesorregião tem, atualmente, sua estrutura produtiva dinamizada, principalmente, pela produção de grãos e pela agroindústria de alimentos. Segundo Westphalen (1987), essa matriz produtiva foi constituída a partir dos movimentos migratórios que ocorreram no início do século XX. 
A região foi formada a partir de 1940 , período de forte fluxo migratório notadamente de famílias do Rio Grande do Sul e Santa Catarina, que estavam em busca de novas fronteiras agrícolas. Tal acontecimento contribuiu para que os espaços vazios dessa região fossem preenchidos e propiciou condições para o início da atividade agrícola desenvolvida pela pequena propriedade, o que trouxe certa estabilidade socioeconômica e cultural à localidade.

O desenvolvimento dos municípios da região deu-se de forma acelerada, convergindo, inicialmente, em torno da economia das comunidades agrícolas. Posteriormente, a partir de 1970, foi implementado em âmbito nacional o processo de modernização da agricultura, e a Mesorregião Oeste do Paraná foi alvo dessa política econômica setorial, acompanhando todas as transformações que atingiram o meio rural, as quais impactaram econômica e socialmente as comunidades agrícolas dessa região.

Segundo o Ipea et al. (2000, p. 109), entre 1970 e 1996,

essa mesorregião passa por processo intenso de urbanização, saltando do grau de 19,87\% para $77,2 \%$. Esse processo provoca grande transformação na distribuição geográfica de sua população: com a área rural da mesorregião alcançando 357.023 habitantes e incrementando suas áreas urbanas com um contingente de 683.175 habitantes, caracterizando-a como uma região receptora de fluxos interiores e exteriores aos seus limites. Vale observar que essa região foi a última fronteira de ocupação do estado, integrando-se à dinâmica estadual apenas a partir dos anos 70, quando coincidem fatores como a expansão da agricultura moderna e o início da construção da Usina Hidrelétrica de Itaipu.

Segundo o Censo Demográfico de 2000, o grau de urbanização nessa região foi de $81,44 \%$, mas com predominância dos pequenos municípios. Do total dos 50 municípios existentes na região, 40 enquadravam-se no perfil de pequenas cidades, inferior a 20 mil habitantes, o que representa $80 \%$ dos municípios.

No Mapa 1, pode-se visualizar a Mesorregião Oeste do Paraná e as principais rodovias que ligam a região à capital do Estado (Curitiba), o acesso ao Sul (Santa Catarina e Rio Grande do Sul) e ao Sudeste e Centro-Oeste do país, bem como os

MAPA 1

Principais rodovias e municípios limítrofes a Cascavel e Toledo Mesorregião Oeste do Paraná - 2003

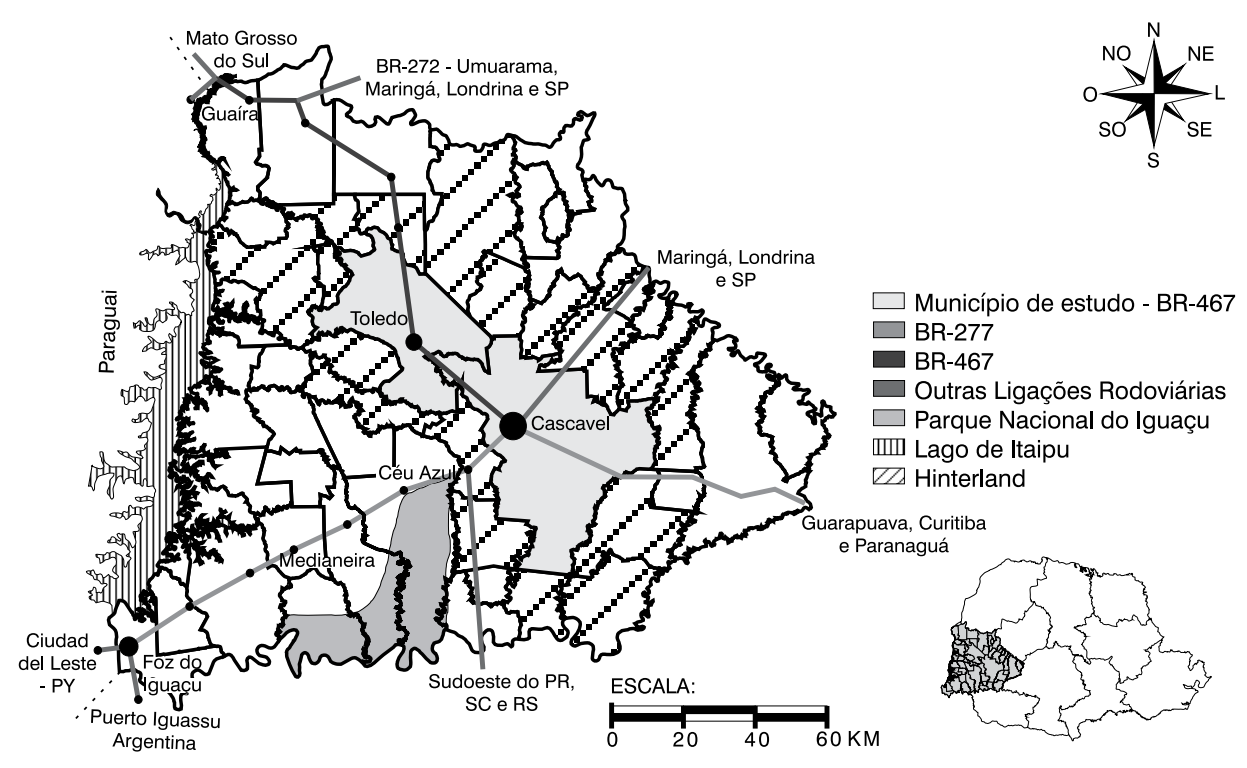

Fonte: IBGE (2003). Elaboração: Stamm (2005). 
acessos internacionais para o Paraguai e a Argentina, através das cidades de Foz do Iguaçu e Guairá. Segundo Moura (2004), passou a existir, no oeste paranaense, um complexo urbano, que articula as aglomerações polarizadas por Cascavel e Foz do Iguaçu e envolve outras cidades menores, tais como Toledo, manifestando-se como uma espacialidade complexa e internacional e desenvolvendo estreitas relações com as cidades vizinhas de Puerto Iguaçu, na Argentina, e Ciudad del Leste, no Paraguai.

As cidades de Cascavel e Toledo figuram-se entre as principais do Estado do Paraná. Cascavel, que possui forte centralidade regional, é o principal pólo de aglomeração na região oeste do Estado, sendo que sua especificidade está em sua localização estratégica - pois ali se encontra o entroncamento de acesso às fronteiras internacionais - e no acúmulo de funções de alta e média complexidade no atendimento às demandas regionais. Já a cidade de Toledo é o centro secundário desse pólo. Assim, Cascavel e Toledo, devido à proximidade geográfica entre si, tornam-se importantes municípios na configuração da rede urbana e no contexto econômico tanto da região oeste como do Estado Paraná. Essa forte associação com a complexidade da rede urbana da região ampliou-se com a implantação da linha do ônibus "metropolitano", 9 o que facilitou o aumento do dinamismo interurbano entre os municípios da região e, particularmente, entre as cidades em estudo, fortalecendo o conceito proposto pelo Ipea (2000) de aglomeração urbana não-contínua. Essas cidades tinham anteriormente acesso entre si por meio do ônibus intermunicipal, mas com a implantação do ônibus metropolitano aumentou a acessibilidade ${ }^{10}$ dos cidadãos dessas cidades aos outros centros urbanos, fundamentalmente dos centros menores para os maiores.
O Mapa 2 mostra o itinerário das empresas que fazem os transportes de passageiros via linha de ônibus metropolitano, abrangendo grande parte da Mesorregião Oeste paranaense. Pode-se observar que todos os municípios lindeiros ao lago de Itaipu estão interligados com esta modalidade de transporte público.

A concessão desse tipo de transporte na região pertencia a três empresas, sendo que a Expresso Princesa dos Campos abrange a maior parcela do mercado, com cerca de $86 \%$ dos municípios atendidos. Vale destacar ainda que os 24 municípios envolvidos no transporte intermunicipal, por meio da empresa Expresso Princesa dos Campos, englobavam cerca de 900 mil pessoas residentes nessas cidades, 0 que correspondia a $81 \%$ do total da população da Mesorregião Oeste, ou 1.111.091 habitantes, segundo o Censo Demográfico de 2000.

O ônibus metropolitano em relação ao intermunicipal pode ter reduzido o conforto dos cidadãos que se movimentam nessas cidades, mas aumentou acessibilidade, devido à redução do custo do transporte. Segundo Borck e Wrede (2005), nos Estados Unidos e Europa, os usuários dos transportes públicos têm subsídios para fazerem o movimento pendular, pagando $25 \%$ das despesas de capital e $50 \%$ dos custos operacionais, respectivamente. Uma análise comparativa parece uma situação distante, mas a implantação do ônibus metropolitano apresenta um efeito similar de redução de custo do transporte e favorece, claramente, a população mais pobre, que guia seu consumo de bens e serviços, quase exclusivamente, via preço.

A pesquisa de campo foi elaborada por amostragem e, para tanto, aplicaram-se questionários estruturados com respostas fechadas para os usuários do ônibus me-

\footnotetext{
${ }^{9}$ Assim chamado esse tipo de transporte na região, ou seja, é linha de ônibus intermunicipal com custos mais baratos em relação às linhas de ônibus intermunicipais convencionais.

$10 \mathrm{O}$ termo mobilidade na literatura vem sendo substituído por um conceito mais amplo, o de acessibilidade. Segundo Pereira (2005), a mobilidade refere-se meramente ao ato de movimentar-se de acordo com as condições físicas e econômicas; um enfoque mais amplo pode ser dado pelo conceito de acessibilidade, que está associado com a oferta do sistema urbano de circulação e a estrutura urbana. Neste conceito agregam-se aspectos relacionados aos grupos sociais, segundo suas características demográficas, atributos indivíduos e socioeconômicos. Por exemplo, a tarifa de ônibus, mesmo considerando o transporte público, é um limitador para a população de baixa renda. Mais detalhes em Weber e Kwan (2003); Alcantra (2001).
} 
MAPA 2

Itinerário dos ônibus metropolitanos

Mesorregião Oeste do Paraná - 2003

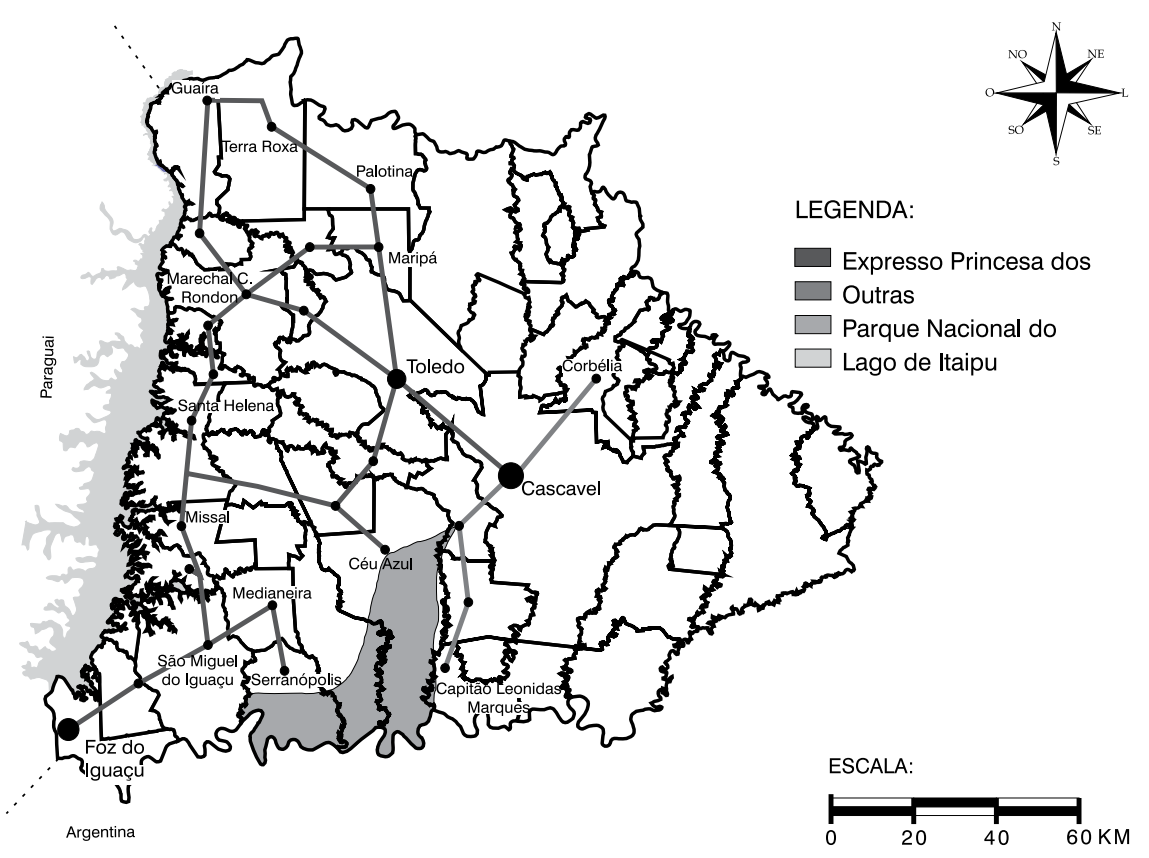

Fonte: IBGE (2003). Elaboração: Stamm (2005).

tropolitano para os dois sentidos: CascavelToledo e Toledo-Cascavel. A Tabela 1 traz uma breve comparação entre o total de passageiros que utilizam o ônibus metropolitano e a população total e a ocupada de Cascavel e Toledo (dados do Censo Demográfico 2000). A média mensal de passageiros transportados pela empresa, entre as cidades de Cascavel e Toledo, correspondia a 12,39\% da população total, ou $28,52 \%$ da população ocupada das duas cidades.

A Tabela 1 revela a existência de um movimento pendular cruzado, ou seja, não está sendo analisada uma situação clássica de único centro ${ }^{11}$ ou policentro, pois a configuração da rede urbana regional da Mesorregião Oeste do Paraná apresentava essa configuração de duas cidades

TABELA 1

Média de passageiros transportados pela Empresa Expresso Princesa dos Campos entre as cidades de Cascavel e Toledo 2005

\begin{tabular}{lccc}
\hline Médias & $\begin{array}{c}\text { Total de } \\
\text { passageiros }\end{array}$ & \% da pop. ocupada & \% da pop. total \\
\hline Média mensal & 42.577 & 28,52 & 12,39 \\
Média semanal & 9.640 & 6,46 & 2,81 \\
Média diária & 1.399 & 0,94 & 0,41 \\
\hline
\end{tabular}

Fonte: IBGE (2000) e Expresso Princesa dos Campos (2005)

11 CDB - Central District Business. 
pólos, com Cascavel em posição superior, tal como sugere o estudo do Ipea (2000). Observou-se, posteriormente confirmado pela pesquisa de campo, que havia uma troca de população que fazia o sentido casatrabalho partindo de ambas as cidades. Naturalmente, em termos relativos, a intensidade do movimento pendular é maior no sentido Toledo-Cascavel; reflexo da escala populacional e da estrutura produtiva mais complexa de Cascavel.

A acessibilidade, nesse estudo, foi analisada principalmente do ponto vista dos citadinos que chegavam a estas duas aglomerações urbanas a partir da rodoviária, havendo de fato o percurso até os seus lares, que é realizado pelos mais diversos meios de transporte, inclusive sistema público de transporte. Do ponto de vista conceitual, para efetivar a análise, segundo Weber e Kwan (2003), a acessibilidade pode se referir a um ponto ou uma zona de localização. No caso deste estudo, a zona que os citadinos pretendem atingir será entendida como a aglomeração urbana das cidades de Cascavel e Toledo, mais especificamente a rodoviária.

A partir dos dados da Tabela 1, foi calculado o tamanho da amostra, considerando a média diária de passageiros entre as cidades. ${ }^{12}$ No entanto, para que a amostra fosse representativa e apresentasse um erro amostral de $5 \%$, foi necessário pesquisar, no mínimo, 311 passageiros. Porém, investigouse um total de 509 passageiros, diminuindo certamente a margem do erro amostral e aumentando a confiança da pesquisa.

Para a aplicação dos questionários foram abordados todos os usuários que utilizavam o chamado "ônibus metropolitano" como meio de locomoção intermunicipal. Esse tipo de transporte tem como lugar de origem o terminal rodoviário das cidades em estudo. Essa etapa da pesquisa foi desenvolvida com a colaboração da empresa Expresso Princesa dos Campos, que permitiu a realização das entrevistas ao lado do guichê da venda de passagens, facilitando a abordagem das pessoas que compravam as passagens para esse tipo de transporte intermunicipal.

Os questionários foram aplicados somente para os passageiros que estavam partindo de seus pontos de origem e, preferencialmente, nos horários da manhã, entre as 6 horas e 12h:30, o que possibilitou captar o perfil dos usuários do ônibus metropolitano e aumentou a probabilidade de entrevistar a parcela de pessoas que fazem o movimento pendular. Além disso, considerou-se o horário matutino mais favorável para a realização da pesquisa, pois o entrevistado estaria mais disposto e seria mais fidedigno às respostas. Os questionários foram aplicados de segunda a sábado da última semana de agosto e na segunda semana de setembro de 2005.

\section{Perfil do movimento pendular de Cascavel-Toledo: usuário do ônibus metropolitano}

A análise inicial dos citadinos que fazem a pendulariedade utilizando o sistema público de transporte nos sentidos Cascavel-Toledo e Toledo-Cascavel revelou que cerca de $70 \%$ estavam empregados, na semana da pesquisa, e os demais eram desempregados, estudantes, ou pessoas que não trabalham. Do total dos empregados (358 entrevistados), praticamente $66 \%$ tinham carteira de trabalho assinada e $34 \%$ trabalhavam na informalidade. Os setores que mais empregavam eram os de prestação de serviços $(19,92 \%)$, comércio de mercadorias $(22,46 \%)$ e indústria de transformação (18,64\%). No entanto, os dois primeiros setores foram, também, os que mais empregavam trabalhadores informais (49,18\% dos ocupados nesta situação).

A Tabela 2 mostra os principais motivos pelos quais os entrevistados estavam se deslocando. O uso do ônibus metropolitano foi justificado pelos usuários que se

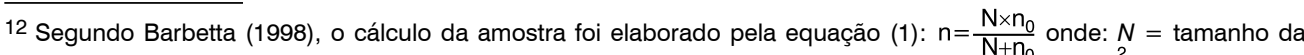
população; $n=$ tamanho da amostra; $n_{0}=$ uma primeira aproximação para o tamanho da amostra; $\mathrm{E}_{0}^{2}=$ erro amostral tolerável.
} 
deslocavam a trabalho (quase $43 \%$ do total de entrevistados) pelo fator econômico/ financeiro, em razão de apresentar um menor custo no deslocamento pendular casa-trabalho-casa.

Outra informação importante é a freqüência diária de deslocamentos da população que utilizava o ônibus coletivo como meio de locomoção (Tabela 3). Do total dos entrevistados, aqueles que utilizavam o ônibus metropolitano poucas vezes, ou seja, menos de uma vez por mês, somavam 18,07\%.

Analisando somente aqueles que se deslocavam por motivos de negócio/trabalho, verifica-se que $27,78 \%$ apresentavam uma freqüência de deslocamento (ida e volta) de cinco vezes por semana, seguido daqueles que se deslocavam uma vez por semana $(14,35 \%)$ - esses normalmente eram os trabalhadores temporários, que passavam a semana fora de sua residência.
As freqüências de deslocamento são variadas, uma vez que os setores econômicos que convergem esses trabalhadores também são diversos, tais como professores, diaristas entre outros tipos de profissão que não necessariamente trabalham todos os dias da semana.

O movimento pendular dos estudantes apresentou um percentual de quase $21 \%$ de movimentos diários (cinco vezes por semana) e de quase $29 \%$ para os que se deslocavam apenas uma vez por semana (esse fato pode ser explicado pelos estudantes universitários que possuem moradias temporárias nas cidades onde estudam). Verificou-se, também, que há um grande fluxo de pessoas que se deslocam entre uma vez por semana e uma vez por mês por motivos familiares.

Observando-se apenas os usuários que naquele momento se deslocavam por causa

TABELA 2

Distribuição dos passageiros que utilizaram o ônibus metropolitano entre as cidades de Cascavel e Toledo, segundo motivo principal

2005

\begin{tabular}{lcc}
\hline Motivos & Passageiros & $\%$ \\
\hline Negócio/trabalho & 216 & 42,44 \\
Turismo/passeio & 51 & 10,02 \\
Visita familiar & 87 & 17,09 \\
Estudo & 69 & 13,56 \\
Saúde & 43 & 8,45 \\
Compras & 5 & 0,98 \\
Outros & 38 & 7,47 \\
Total & $\mathbf{5 0 9}$ & $\mathbf{1 0 0 , 0 0}$ \\
\hline
\end{tabular}

Fonte: Stamm (2005).

TABELA 3

Distribuição dos passageiros que utilizaram o ônibus metropolitano entre as cidades de Cascavel e Toledo, por principal motivo, segundo freqüência 2005

\begin{tabular}{|c|c|c|c|c|c|c|c|c|}
\hline \multirow{3}{*}{ Freqüências } & \multirow{2}{*}{\multicolumn{7}{|c|}{ Principal motivo }} & porcentag \\
\hline & & & & & & & & \multirow[b]{2}{*}{ Total } \\
\hline & $\begin{array}{l}\text { Negócio/ } \\
\text { trabalho }\end{array}$ & $\begin{array}{l}\text { Turismo/ } \\
\text { passeio }\end{array}$ & $\begin{array}{c}\text { Visita } \\
\text { familiar }\end{array}$ & Estudo & Saúde & Compras & Outros & \\
\hline 1 vez por semana & 14,35 & 17,65 & 18,39 & 28,99 & 4,65 & - & 13,16 & 16,31 \\
\hline 2 vezes por semana & 10,19 & 1,96 & 8,05 & 17,39 & 2,33 & - & 5,26 & 8,84 \\
\hline 3 vezes por semana & 8,33 & 1,96 & 5,75 & 4,35 & - & - & 10,53 & 6,09 \\
\hline 4 vezes por semana & 2,78 & 1,96 & 2,30 & 2,90 & - & - & - & 2,16 \\
\hline 5 vezes por semana & 27,78 & - & 1,15 & 20,29 & 2,33 & - & 2,63 & 15,13 \\
\hline 6 vezes por semana & 10,65 & - & - & 1,45 & - & - & - & 4,72 \\
\hline 7 vezes por semana & 3,24 & - & 1,15 & -0 & 2,33 & - & - & 1,77 \\
\hline 1 vez a cada 15 dias & 9,72 & 27,45 & 11,49 & 13,04 & 23,26 & - & 13,16 & 13,56 \\
\hline 1 vez por mês & 5,09 & 17,65 & 26,44 & 8,70 & 16,28 & 60,00 & 23,68 & 13,36 \\
\hline Outras & 7,87 & 31,37 & 25,29 & 2,90 & 48,84 & 40,00 & 31,58 & 18,07 \\
\hline Total & 100,00 & 100,00 & 100,00 & 100,00 & 100,00 & 100,00 & 100,00 & 100,00 \\
\hline
\end{tabular}

Fonte: Stamm (2005). 
de negócios/trabalho (216 entrevistados, ou $42,44 \%$ do total), foram registrados motivos diversos que os levaram a trabalhar em outra cidade (Tabela 4).

Entre os motivos selecionados, os mais citados foram a pouca oferta de trabalho na cidade onde os entrevistados residem $(31,48 \%)$ e a melhor oferta salarial para trabalhar em outra cidade (30,09\%). Ainda em relação à distribuição de motivos, $16,20 \%$ eram trabalhadores temporários, podendo ser viajantes, promotores de venda e, principalmente, aqueles que trabalham na construção civil, entre outros. Ressalta-se que $10,65 \%$ correspondiam a trabalhadores que passaram em concursos e $6,94 \%$ referiam-se àqueles que foram transferidos pelas empresas para alguma filial ou mesmo para a matriz.

A Tabela 5 apresenta a distribuição dos trabalhadores pendulares, segundo os setores de atividades econômicas em que estão inseridos. Pode-se inferir que grande parte dos trabalhadores encontrava-se empregada no comércio de mercadorias ou nas atividades de prestação de serviços. A maioria dos trabalhadores pendulares
(68\%) distribuía-se em apenas quatro dos onze setores de atividades: comércio de mercadorias $(21,30 \%)$; prestação de serviços $(25,93 \%)$; indústria da transformação (10,65\%); e construção civil (10,19\%). Porém, se forem somados mais dois setores - transporte e administração pública -, esse percentual aproxima-se a $85 \%$ do total de trabalhadores nesses seis setores. De maneira geral, o comportamento da ocupação detalhada reflete a mudança da estrutura econômica dessas duas cidades, que tiveram acelerada urbanização, mesmo localizadas distantes das grandes aglomerações populacionais brasileiras e a despeito de a produção agropecuária ainda apresentar peso expressivo na economia dos dois municípios.

Observou-se que mais da metade dos entrevistados $(78,24 \%)$ possuía um rendimento do trabalho de até quatro salários mínimos e 47,69\% registravam essa mesma faixa como renda familiar (Tabela 6). Desta forma, quando comparado com sua renda familiar, observou-se que houve uma diminuição do total de pessoas com renda até quatro salários mínimos, com aumento

TABELA 4

Distribuição dos passageiros que utilizaram o ônibus metropolitano entre as cidades de Cascavel e Toledo por causa de negócio/trabalho, segundo motivos 2005

\begin{tabular}{lr}
\hline Motivos & $\%$ \\
\hline Pouca oferta de trabalho onde reside & 31,48 \\
Salário melhor & 30,09 \\
Trabalho temporário & 16,20 \\
Passou em concurso & 10,65 \\
Transferido & 6,94 \\
Outros & 4,64 \\
Total & $\mathbf{1 0 0 , 0 0}$ \\
\hline
\end{tabular}

Fonte: Stamm (2005).

TABELA 5

Distribuição dos passageiros que utilizaram o ônibus metropolitano entre as cidade de Cascavel e Toledo por motivo de trabalho/negócio, segundo setores de atividades 2005

\begin{tabular}{lc}
\hline Setores de atividades & $\%$ \\
\hline Agricultura/pecuária/silvicultura & 1,85 \\
Indústria de transformação & 10,65 \\
Construção civil & 10,19 \\
Comércio de mercadorias & 21,30 \\
Prestação de serviços & 25,93 \\
Transporte e comunicação & 8,80 \\
Atividades sociais & 4,17 \\
Administração pública & 7,87 \\
Serviços auxiliares & 3,24 \\
Outras atividades & 6,02 \\
Total & $\mathbf{1 0 0 , 0 0}$ \\
\hline
\end{tabular}

Fonte: Stamm (2005). 
expressivo daqueles que se encontravam na faixa de renda entre 8 e 10 salários. Alguns membros das famílias deslocavam-se para trabalhar em outra cidade e os demais trabalhavam na mesma cidade que moravam, ou poderiam estar também trabalhando em cidades vizinhas.

$\mathrm{Na}$ Tabela 6, fica evidenciado que os trabalhadores que faziam o movimento pendular utilizando o ônibus metropolitano eram as pessoas preponderantemente de renda baixa, cerca de $78 \%$. Por outro lado, apenas $4,63 \%$ recebiam mais de dez salários mínimos. Provavelmente, as pessoas de faixa de renda mais alta fazem o movimento pendular com carro próprio.

Os citadinos ocupados que realizavam o movimento pendular mencionaram vários motivos para não migrarem para a cidade onde trabalhavam, destacando-se: os familiares $(34,72 \%)$; os pessoais, por gostarem da cidade onde residem atualmente $(21,76 \%)$; e marido/esposa trabalha na cidade onde reside $(10,19 \%)$. A soma do primeiro e terceiro motivos pode ser agrupada como motivações associadas à questão familiar de quase $45 \%$ dos entrevistados. Essas razões para o local de moradia estão ligadas à rede social de proteção primária da sociedade, que é a família. $O$ aspecto econômico associado ao custo de vida não apareceu como um motivo tão expressivo (5,09\%), da mesma forma como se verifica nos estudos de movimento populacional realizados nas grandes cidades e metrópoles.

As evidências reveladas pela Tabela 7 estão no mesmo sentido das reflexões de Fishman (1990, p. 38): "as famílias criam suas 'própria cidades'”. Dessa forma, considerando-se a percepção de Fishman
(1990), pode-se agrupar as três primeiras motivações, que correspondem a $66,67 \%$ das razões para os indivíduos não mudarem da cidade com suas famílias, porque a idéia de gostar do local de moradia está associada a várias relações de sociabilidade da família com o lugar onde vive, e o indivíduo não está disposto em desconstruí-las para construir em outro local. Weber e Kwan (2003) asseveram que a acessibilidade deve refletir mais as características particulares individuais e das famílias em vez de uma unidade espacial em comum.

A distância como um dos aspectos que influencia a capacidade humana de fazer movimento pendular tem sido questionada, entretanto, segundo Rouwendal (2004), há uma distância limite para o citadino perfazê-lo, pois, caso essa seja excedida, o trabalhador reagirá adaptando-se a outro trabalho ou residência. Os dados da Tabela 7 evidenciam que a distância entre Cascavel e Toledo deve está dentro desse limite para os citadinos de ambas as cidades.

A pendulariedade é motivada pela construção de relações sociais no âmbito da família e com os vizinhos, estabelecidas na cidade de origem. Além disso, deve-se considerar a frágil relação de trabalho, atualmente, na economia brasileira e mundial. A permanência em um posto de trabalho está cercada ora por perspectivas positivas ora por perspectivas negativas, o que gera incertezas quanto a uma iminente demissão. Esta situação contribui para que os trabalhadores tenham muita cautela na decisão de se mudar para próximo ao local de trabalho, nesse caso a cidade. A implementação do ônibus metropolitano, em 2002, e o fim da duplicação da rodovia que interliga as

TABELA 6

Distribuição dos passageiros que utilizaram o ônibus metropolitano entre as cidades de Cascavel e Toledo por motivo de trabalho/negócio, por faixa salarial e renda familiar

2005

\begin{tabular}{lrc}
\hline Faixas & \multicolumn{2}{c}{ Trabalhadores } \\
\cline { 2 - 3 } & Salarial & Renda familiar \\
\hline Até 1 salário mínimo & 11,57 & 4,63 \\
2 a 4 salários mínimos & 66,67 & 43,06 \\
5 a 7 salários mínimos & 12,04 & 29,63 \\
8 a 10 salários mínimos & 5,09 & 14,81 \\
Mais de 10 salários mínimos & 4,63 & 7,87 \\
Total & $\mathbf{1 0 0 , 0 0}$ & $\mathbf{1 0 0 , 0 0}$ \\
\hline
\end{tabular}

Fonte: Stamm (2005). 
cidades de Cascavel e Toledo, em 2007, melhoraram as condições de acessibilidade, aumentando, dessa forma, as barreiras que poderiam transformar o movimento pendular em migração definitiva.

$\mathrm{O}$ acesso a bens e serviços não se estampou como uma resposta nos motivos para o individuo não migrar. Isto se deve, provavelmente, ao fato de que as duas cidades apresentam uma série de bens e serviços razoavelmente substitutos. Além disso, a acessibilidade melhorou, havendo hoje certa facilidade de locomoção entre as cidades, sem muitos transtornos e de baixo custo, possibilitando o acesso a outros tipos de bens e serviços que não estejam disponíveis no mercado local.

Aspecto importante para o movimento pendular é o tempo gasto no trajeto casatrabalho. Os trabalhadores que faziam esse deslocamento gastavam, em média, 79 minutos entre a casa e o seu local de trabalho. Já o tempo médio calculado para os estudantes pendulares foi de, praticamente, 77 minutos (Tabela 8 ).
Pode-se considerar uma média de tempo elevada entre Cascavel e Toledo, haja vista o tamanho das cidades quando comparadas com a Região Metropolitana de São Paulo (RMSP). Segundo Antico (2003), nessa região metropolitana, o tempo médio de deslocamento, para os citadinos que faziam o movimento pendular, em transportes coletivos, era de 77,7 minutos. Porém, deve-se ressaltar que, no cálculo do tempo médio na RMSP, a autora considerou vários tipos de transporte (carro, trem, metrô, ônibus fretado, entre outros). No estudo dos deslocamentos pendulares, além da distância percorrida, devem ser incluídos os meios de transporte utilizados, a infra-estrutura e a acessibilidade para tais deslocamentos, independente da região analisada. Neste caso, em específico, se fosse utilizada apenas a média dos transportes com ônibus coletivos da RMSP, provavelmente a média de tempo para os deslocamentos seria bem superior à apresentada, corroborando, dessa forma, a observação de Gordon, Kumar e Richardson (1989), de que os movimentos

TABELA 7

Distribuição dos passageiros que utilizaram o ônibus metropolitano entre as cidades de Cascavel e Toledo por motivos de trabalho/negócio, segundo razões para não migrarem para a cidade onde trabalham 2005

\begin{tabular}{lc}
\hline Razóes para não migrarem & $\%$ \\
\hline Outros motivos familiares & 34,72 \\
Gosta da cidade onde mora & 21,76 \\
Marido/esposa trabalha na cidade onde residem & 10,19 \\
Estuda na cidade onde reside & 4,63 \\
Viajante & 10,19 \\
Violência & 2,78 \\
Trabalho temporário & 3,24 \\
Custo de vida mais elevado & 5,09 \\
Outros motivos & 7,41 \\
Total & $\mathbf{1 0 0 , 0 0}$ \\
\hline
\end{tabular}

Fonte: Stamm (2005).

TABELA 8

Distribuição dos trabalhadores e estudantes que utilizaram o ônibus metropolitana entre as cidades de Cascavel e Toledo, segundo tempo médio gasto no movimento

2005

\begin{tabular}{lcc}
\hline Tempo médio & Trabalhadores & Estudantes \\
\hline Menos de 1/2 hora & 5,56 & 4,35 \\
$1 / 2$ hora & 7,41 & 13,04 \\
1 hora & 15,28 & 10,14 \\
1 h e 15 minutos & 21,76 & 27,54 \\
1 h e 30 minutos & 25,00 & 31,88 \\
Mais que 1h e 30 minutos & 25,00 & 13,04 \\
Total & $\mathbf{1 0 0 , 0 0}$ & $\mathbf{1 0 0 , 0 0}$ \\
\hline
\end{tabular}

Fonte: Stamm (2005). 
pendulares tendem a ser mais demorados em cidades de grande porte populacional do que nas de menor porte.

A predominância do tempo gasto para o deslocamento pendular diário - a somatória do tempo de ida para o trabalho e de volta para casa -, tanto de trabalhadores como para estudantes, foi uma média superior a 2 horas e 30 minutos, evidenciando um grande tempo despendido no dia-a-dia dessas pessoas. A otimização do sistema urbano com duplicação não foi capitada nessa pesquisa e, sem dúvida, deve reduzir esse tempo total de deslocamento dos citadinos.

\section{Conclusões}

Esse trabalho procurou examinar o fenômeno dos movimentos pendulares dos trabalhadores intermunicipais entre as cidades interioranas de porte médio de Cascavel e Toledo, localizadas na Mesorregião Oeste do Estado do Paraná.

A pesquisa revela que os principais motivos que levaram os trabalhadores a obterem emprego em outra cidade e fazer o movimento pendular foram a pouca oferta de emprego na cidade onde residiam e a oferta de melhores salários na cidade vizinha. $\mathrm{O}$ fator econômico ligado diretamente à questão do emprego está relacionado às teorias de migrações internas e de movimento pendular, ${ }^{13}$ pois grande parte das pesquisas sobre movimentos pendulares apresenta como principal motivo para tais deslocamentos diários a questão econômica.

Segundo as teorias que abordam os movimentos pendulares e as migrações internas, o trabalhador tende a residir em moradia menos cara, decisão que convém devido ao elevado custo da habitação na área central da cidade. Em áreas metropolitanas, os trabalhadores chegam a ultrapassar os limites administrativos da cidade em que trabalham para se fixarem em moradias de menor custo. Portanto, leva-se em consideração principalmente o fator econômico na decisão de migrar.
Já em cidades interioranas de porte médio, tais como Cascavel e Toledo, foi constatado que a maioria dos trabalhadores entrevistados não migrava para a cidade que trabalhavam motivados por questões familiares e porque gostavam da cidade onde residiam. Esses dois fatores estão relacionados à vida social dos citadinos. $\mathrm{A}$ cidade configura-se e tece relações sociais ao longo do tempo, possibilitando a seus habitantes criarem ou fortalecerem laços sociais com os próprios membros da família e com os vizinhos, bem como nos espaços públicos. Nessa pesquisa, apenas um pequeno grupo de entrevistados apresentou o fator econômico como motivo principal na decisão para não migrar para a cidade em que trabalhava.

Acredita-se que, à medida que o citadino tenha capacidade individual de movimentar-se, ele estará morando no local que preencha suas expectativas. A própria insegurança em relação ao trabalho motiva este movimento de troca diária de população entre os municípios de Cascavel e Toledo.

Ressalta-se então que a rede primária de proteção social (a família) torna-se um fator importante e particular para as cidades interioranas de porte médio de Cascavel e Toledo. Este fato é, provavelmente, menos presente nas cidades de maior porte populacional. A desagregação familiar pode ser um item importante para ser examinado com mais profundidade na comparação entre cidades de igual ou diferentes tamanhos em novos estudos.

O movimento pendular de trabalhadores registrado entre as cidades interioranas de Cascavel e de Toledo não é exclusivo das grandes aglomerações urbanas ou regiões metropolitanas. Observou-se que está se estabelecendo uma nova face da urbanização brasileira, fundamentalmente, na dinâmica das redes urbanas e, em particular, nas cidades interioranas de porte médio que ativam novas funções com as suas hinterland.

\footnotetext{
13 Tais como os trabalhos de: Beaujeu-Garnier (1974), George (1983), Pisco (1997), INE (2003b), Grando (2005), Renkow, Hoover e Yoder (1996), entre outros.
} 
No caso desse estudo, verificou-se uma pendularidade cruzada, pois não há um movimento exclusivo de uma cidade para outra no sentido casa-trabalho; nos dois municípios ocorre o movimento pendular casa-trabalho. Este tipo de situação está associado à formação da rede urbana, sendo necessária uma configuração de pólos regionais suficientemente próximos para que o custo e o tempo do transporte estejam dentro de um limite de tolerância para os trabalhadores.

Este estudo apresentou algumas limitações, sendo fundamental a realização de novos estudos que persigam questões mais

\section{Referências bibliográficas}

ALCANTRA, E. Transporte urbano, espaço e equidade: análise das políticas públicas. São Paulo: Annablume, 2001.

ANDRADE, T. A.; SERRA, R. V. O recente desempenho das cidades médias no crescimento populacional urbano brasileiro. Rio de Janeiro: Ipea, 1997 (Relatório de pesquisa do projeto Crescimento Econômico e Desenvolvimento Urbano).

ANTICO, C. Onde morar e onde trabalhar: espaço e deslocamento pendulares na Região Metropolitana de São Paulo (Tese de Doutorado). Campinas: Unicamp, 2003.

. Mobilidade populacional diária no município de São Paulo. In: ENCONTRO NACIONALDE ESTUDOS POPULACIONAIS, XII. Caxambu. Anais... Belo Horizonte: Abep, v. $1,2000$.

BAENINGER, R. A. Deslocamentos populacionais, urbanização e regionalização. Revista Brasileira de Estudos de População, Belo Horizonte, Abep, v. 15, 1999.

. Movimentos migratórios no contexto paulista: tendências da década de 80. In: ENCONTRO NACIONAL DE ESTUDOS POPULACIONAIS, X. Caxambu. Anais... Belo Horizonte: Abep, v. 2, 1996.

BARBETTA, P. A. Estatística aplicada às ciências sociais. 2. ed. Florianópolis: Ed. da UFSC, 1998. específicas, pautadas, por exemplo, em outras formas de deslocamentos pendulares através de carros, vans e ônibus fretados, além de novos estudos acerca das formas e perspectivas de crescimento das cidades interioranas de porte médio no Brasil. Este tipo de pesquisa e análise tende a ganhar robustez por meio de acompanhamento ao longo do tempo para verificar seu comportamento. Novas pesquisas ainda poderão ser elaboradas para outras regiões, no sentido de determinar algumas recorrências e regularidades, pois este movimento pendular afeta a vida das pessoas, as cidades e a configuração das redes urbanas.

BEAUJEU-GARNIER, J. Geografia de população. São Paulo: Editora Nacional, 1974.

BORCK, R.; WREDE, M. Political economy commuting subisideos. Journal Urban Economic, n. 57, p.478-499, 2005.

BRITO, F.; HORTA, C. J. G.; AMARAL, E. F. de $L$. A urbanização recente no Brasil e as aglomerações metropolitanas. Associação Brasileira de Estudos Populacionais - Abep. Anais... 2001. Disponível em: <http://www. abep.org.br/usuario/GerenciaNavegacao. php?caderno_id $=362 \&$ nivel $=1$ \&texto_ $\mathrm{id}=2092>$. Acesso em: $18 \mathrm{dez} .2004$.

CARLOS, A. F. A. A cidade. 5. ed. São Paulo: Contexto, 2001.

CARVALHO, J. A. M.; RIGOTTI, J. I. R. Os dados censitários brasileiros sobre migrações internas: algumas sugestões para análise. In: ENCONTRO NACIONAL DE ESTUDOS POPULACIONAIS, XI. Anais... Belo Horizonte, Abep, 1998.

CARVALHO, S, N. de; BARRETA, S. A. A mobilidade pendular e intramunicipal dos estudantes e ocupados na região metropolitana de São Paulo: subsídios à formulação de políticas em transporte urbano. In: ENCONTRO NACIONAL DE ESTUDOS POPULACIONAIS, XI. Anais... Belo Horizonte, Abep, 1998.

DEMATTEIS, G. Suburbanización y periurbanización: ciudades anglosajonas 
y ciudades latinas. Disponível em: <http://www.xcosta.arq.br/atlas/debate/ ciudadispersa_2.htm $>$. Acesso em: 27 jun. 2005.

FISHMAN, R. Megalopolis unbound. The Wilson Quarterly, v. 14, p.25-45, 1990.

GALVÃO, M. V. et al. Áreas de pesquisas para determinação de áreas metropolitanas. Revista Brasileira de Geografia, v. 31, n. 4, p. 53-140, out./dez., 1969.

GEORGE, P. Geografia urbana. São Paulo: Difel, 1983.

GORDON, P.; KUMAR, A.; RICHARDSON, $\mathrm{H}$. W. The influence of metropolitan spatial structure on commuting time. Journal of Urban Economics, n. 26, p. 138-151, 1989.

GRANDO, P. J. Elementos e conceitos demográficos fundamentais. Disponível em: < http://ftp.sj.univali.br/prof/Paulo\%20 Jonas\%20Grando/texto\%20de mografia. doc>. Acesso em: 14 mar. 2005.

HANSON, S.; PRATT, G. Reconpetualizing the links between home and work in urban geography. Economic Geography, v.64, 299-321, 1988.

HORNER, M. W. Spatial dimensions of urban commuting: a review of major issues and their implications future geographic research. The Professional Geographer, v.56, n. 2, p.160-173, 2003.

IBGE - Instituto Brasileiro de Geografia e Estatística. Características dos municípios. Disponível em: <http://www.ibge.gov.br/ ibgeteen/pesquisas/geo/municipios.html>. Acesso em: 15 abr. 2005.

\section{Base cartográfica integrada} do Brasil ao milionário digital (BCIMD) - 2003, 1ำ versão digital. Rio de Janeiro, nov. 2003.

Janeiro: IBGE, 2000.

INE - Instituto Nacional de Estatística. Sistema urbano: áreas de influência e marginalidade funcional: região Centro. Lisboa, Portugal: INE, 2004.
Movimentos pendulares e organização do território metropolitano: área metropolitana de Lisboa e área metropolitana do Porto: 1991/2001. Lisboa, Portugal: INE, 2003a.

Mobilidade casa-trabalho da população empregada residente na área metropolitana do Porto: 2000. Porto, Portugal: Instituto Nacional de Estatística, Direcção Regional do Norte, 2003b.

IPEA; UNICAMP/IE/NESUR; IBGE (Orgs.). Série caracterização e tendências da rede urbana do Brasil. Estudos básicos para a caracterização da rede urbana. Campinas: Unicamp/IE, v. 2, 2002.

IPEA; IBGE; UNICAMP/IE/NESUR; IPARDES (Orgs.). Caracterização e tendências da rede urbana do Brasil: redes urbanas regionais - Sul. Brasília: Ipea, v. 6, 2000.

IPEA; UNICAMP/IE/NESUR; IBGE (Orgs.). Caracterização e tendências da rede urbana do Brasil. Campinas: Unicamp/IE, 1999 (Coleção Pesquisas, 3).

MAGALHÃES, D. J. A. V. de; D'AVILA, A. E. C. Migrações dentro da região metropolitana de Belo Horizonte visando moradia próxima ao local de trabalho. In: ENCONTRO NACIONALDE ESTUDOS POPULACIONAIS, $X$, Caxambu. Anais... Belo Horizonte: Abep, v. 2, 1996.

MATOS, C. Migrações: decisões individuais e estruturas sociais. Socius Working Papers - Centro de Investigação em Sociologia Económica e das Organizações Instituto Superior de Economia e Gestão. Universidade Técnica de Lisboa, 1993. Disponível em: <http://pascal.iseg.utl. $\mathrm{pt} / \sim$ socius/index.htm>. Acesso em: 25 jan. 2005.

MOREIRA, E. V. A pluriatividade nos espaços periurbanos: um enfoque geográfico no município de Presidente Prudente - SP. In: COLÓQUIO INTERNACIONAL DE GEOCRÍTICA, X. Anais... Santiago de Chile, 24-27, maio 2005.

MOURA, R. Paraná: meio século de urbanização. Revista RA'E GA, Curitiba, Editora UFPR, n. 8, p. 33-44, 2004. 
OECED. Redefining territories: the functions regions. Paris: OECED, 2002.

OMMEREN, J. van; RIETVELD, P.; NIJKAMP, $P$. Job moving, residential moving, and commuting: a searching perspective. Journal of Urban Economics, v. 46, p. 230-253, 1999.

PATARRA, N.; BAENINGER, R.; CUNHA, J. M. P. Dinâmica demográfica recente e a configuração de novas questões populacionais. In: PACHECO, C. A.; PATARRA, N. (Orgs.). Dinâmica demográfica regional e as novas questões populacionais no Brasil. Campinas: Unicamp/IE, 2000.

PEREIRA, S. R. Percursos urbanos: mobilidade e a acessibilidade. In: SIMPÓSIO INTERNACIONAL DE CIDADES MÉDIAS, II. Anais... Uberlândia, 2006.

PISCO, M. L. Migrações pendulares: unidades geográficas de emprego. Lisboa: Edição do Departamento de Prospectiva e Planejamento Núcleo de Informação e Comunicação, 1997.

RENKOW, M.; HOOVER, D. M. Commuting, migration, and rural-urban population dynamics. Journal of Regional Science, v. 40, n. 2, p. 261-287, 2000.

RENKOW, M.; HOOVER, D. M.; YODER, $\mathrm{J}$. Commuting and migration in North Carolina: does suburbanization explain the trends? North Carolina: Department of Agricultural and Resource Economics North Carolina State University, 1996.
REOLON, C. A. A aglomeração urbana da soja: Cascavel e Toledo no contexto da metropolização na Mesorregião Oeste do Paraná. (Dissertação de mestrado). ToledoPR: Unioeste/CCSA, 2007.

STAMM, C. O fenômeno dos movimentos pendulares dos trabalhadores intermunicipais entre cidades de porte médio: 0 caso de Cascavel e Toledo (PR). Dissertação (Mestrado em Desenvolvimento Regional e Agronegócio). Toledo-PR, Universidade Estadual do Oeste do Paraná - Unioeste/ Campus de Toledo, 2005

ROUWENDAL, J. Search theory and commuting behavior. Growth and Change, v. 33, n.3, Summer, p. 391-418, 2004

VALES, A. Definido o conceito e descobrindo a plurifuncionalidade do espaço periurbano. 2004. Disponível em: < http:// www.lead.uerj.br/VICBG-2004/eixo3/E3 017. htm>. Acesso em: 15 jan. 2005.

VANDERSMISSEN, M.-H.; VILLENEUVE, P.; THÉRIAULT, M. Analyzing changes in urban form and commuting time. The Professional Geographer, v. 55, n. 4, nov. 2003.

WEBER, J.; KWAN, M.-P. Evaluating the effects of geographic contexts on individual accessibility: a multilevel approach. Urban Goegraphy, v.24, n.8, p. 647-671, 2003.

WESTPHALEN, C. M. História documental do Paraná: primórdios da colonização moderna da região de Itaipu. Curitiba: SBPH-PR, 1987.

\section{Resumen}

Movimientos pendulares de las ciudades del interior de porte medio de Cascavel y Toledo, en Paraná

El objetivo de este artículo es examinar el fenómeno del movimiento pendular de trabajadores intermunicipales entre las ciudades del interior de porte medio de Cascavel y Toledo, localizadas en la Mesoregión Oeste del Estado de Paraná. La dinámica económico-poblacional de las distintas regiones del interior de Brasil viene imprimiendo nuevas modalidades de desplazamientos poblacionales, las cuales eran casi exclusivas de los grandes centros urbanos. Los estudios de esta naturaleza se tornan importantes, pues exponen informaciones relevantes para la planificación urbano-regional y en el ordenamiento de la dinámica territorial. El movimiento pendular observado en este estudio es del tipo cruzado, lo que significa que hay movimiento casa-trabajo originado en las dos ciudades, en razón de ser ambas polos 
regionales. El resultado de la investigación evidenció que la red primaria de protección social (la familia) es un factor importante y, en particular, en las ciudades de porte medio, como es el caso de Cascavel y Toledo. El flujo de trabajadores pendulares entre Cascavel y Toledo presenta un papel fundamental en el diseño de la red urbana de la región. De esta forma, se verificó que algunos asuntos urbanos que se presentan en los grandes centros urbanos y en las regiones metropolitanas del país, tales como los movimientos pendulares, son también temas importantes para las ciudades de menor porte poblacional.

Palabras-Clave: Movimiento pendular. Ciudades de porte medio. Red urbana.

\begin{abstract}
Commuting in medium-size cities of Cascavel and Toledo, Paraná

This article analyzes the phenomenon of inter-city commuting between the cities of Cascavel and Toledo in the western meso-region of the State of Paraná, Brazil. The economic and populational dynamics in various areas in Brazil are showing new modalities of mobility of the population, since, until recently, such phenomena had been present almost exclusively in large cities. It is important to study this aspect in order to provide for better urban-regional planning and territorial organization. The commuting between Cascavel and Toledo is of the crossed-type because the commuters are from both cities. The results of this research showed that the primary social protection net (the family) is an important factor in medium-size cities such as Cascavel and Toledo. The commuting between the two cities plays an important role in the urban format of the region. It is thus clear that some aspects of urbanization that once were seen almost exclusively in metropolitan areas are now important issues for medium-sized cities as well.
\end{abstract}

Keywords: Commuting. Medium-size cities. Urban system.

Recebido para publicação em 08/05/2007. Aceito para publicação em 25/04/2008. 